\section{BMJ Open}

Ophthalmology

\title{
Outcomes and surgical management of persistent fetal vasculature
}

\author{
Nikhila Khandwala, ${ }^{1}$ Cagri Besirli, ${ }^{1}$ Brenda L Bohnsack (i) ${ }^{2,3}$
}

To cite: Khandwala N, Besirli C, Bohnsack BL. Outcomes and surgical management of persistent fetal vasculature. BMJ Open Ophthalmology 2021;6:e000656. doi:10.1136/ bmjophth-2020-000656

- Additional supplemental material is published online only. To view, please visit the journal online (http://dx.doi. org/10.1136/bmjophth-2020000656).

Received 6 November 2020 Revised 13 March 2021 Accepted 16 April 2021

\section{Check for updates}

\section{(c) Author(s) (or their}

employer(s)) 2021. Re-use permitted under CC BY-NC. No commercial re-use. See rights and permissions. Published by BMJ.

${ }^{1}$ Department of Ophthalmology and Visual Sciences, University of Michigan, Ann Arbor,

Michigan, USA

${ }^{2} 0$ phthalmology and Visual Sciences, Ann and Robert H Lurie Children's Hospital of Chicago, Chicago, Illinois, USA ${ }^{3}$ Ophthalmology, Northwestern University Feinberg School of Medicine, Chicago, Illinois, USA

Correspondence to Dr Brenda L Bohnsack; bbohnsack@luriechildrens.org

\section{ABSTRACT}

Objective To analyse outcomes in different forms of persistent fetal vasculature (PFV).

Methods and analysis Retrospective cohort study at a university-based practice of children presenting with PFV between 2011 and 2020. Exclusion criteria was surgical management outside of our institution and follow-up less than 1 month. Wilcoxon and Student's t-tests were used for statistical analysis.

Results Forty-six eyes of 45 patients presented with PFV at $16.7 \pm 31.3$ (median 2.8) months old with $32.6 \pm 29.8$ (median 22.5) months of follow-up. Types of PFV included: mild combined anterior-posterior (23 eyes, 50\%), severe combined anterior-posterior (18 eyes, 39\%), severe anterior ( 3 eyes, $7 \%$ ), mild anterior ( 1 eye, $2 \%$ ) and posterior (1 eye, 2\%). Thirty-two eyes (70\%) underwent PFV surgical correction; lensectomy (13 mild combined), vitrectomy ( 3 mild combined), sequential lensectomy then vitrectomy (3 severe combined), combined lensectomyvitrectomy (11 severe anterior or severe combined), laser retinopexy (1 mild combined). Five eyes required additional vitrectomy surgery for retinal detachment, fold or cyclitic membrane. Nine eyes developed glaucoma, six requiring Intraocular pressure (IOP)-lowering surgery. At final follow-up, 32 eyes had at least form vision and 6 eyes were aversive to light. Eight eyes, all which were severe combined, and four that did not undergo PFV surgery, were unable to detect light due to phthisis bulbi (7) and optic nerve hypoplasia (1).

Conclusions Classification of PFV is important in determining surgical approach with severe cases often requiring both lensectomy and vitrectomy for optimal anatomic and functional outcomes.

\section{BACKGROUND}

Persistent fetal vasculature (PFV), which is a result of failed regression of the embryonic ocular vasculature, causes significant visual morbidity and accounts for $5 \%$ of childhood blindness in the USA. ${ }^{2}$ The majority of cases are idiopathic and unilateral with no identified genetic cause. Rare autosomal recessive mutations in $A T O H 7$ have been identified in familial non-syndromic bilateral PFV. ${ }^{3}{ }^{4}$ Further, bilateral cases can be connected to systemic syndromes such as neurofibromatosis type 2, Aicardi syndrome, osteoporosis-pseudoglioma syndrome and chromosomal aneuploidies including trisomy 13,15 and $18 .^{5-11}$ PFV can also be associated

\section{Key messages}

What is already known about this subject?

Persistent fetal vasculature (PFV) is classified by location as well as severity.

- Many of these eyes require surgical treatment to optimise visual potential and decrease risk of complications such as retinal detachment and glaucoma.

\section{What are the new findings?}

- Classification and severity of the PFV dictates the surgical approach and visual outcome.

- Mild cases may be managed with observation, lensectomy or lens-sparing vitrectomy.

- For severe cases of anterior and combined anteriorposterior PFV, a combined lens extraction with full vitrectomy approach was most effective in restoring anatomy and minimising complications.

\section{How might these results change the focus of} research or clinical practice?

- Careful classification and determination of severity of PFV is important in managing these challenging cases.

A combined approach with anterior and posterior segment paediatric ophthalmic surgeons is effective in establishing vision in severe cases of PFV.

with retinopathy of prematurity and other congenital ocular abnormalities including Axenfeld-Rieger Syndrome and Peters Anomaly. ${ }^{12-14}$

PFV is classified by location as well as severity (table 1) and typically presents as leucocoria with microphthalmia. Additional findings include glaucoma, cataract, corneal opacification, coloboma, retinal fold, retinal detachment, and spontaneous retinal and vitreous haemorrhages. ${ }^{15} 16$ The surgical approach is primarily guided by the type of PFV and secondarily by the associated ocular comorbidities, taking into context the likely visual potential of the eye, the amount of amblyopia and refractive management. ${ }^{2} 17$ Surgery intends to restore anatomy and maximise vision by establishing the visual axis and managing complications. Mild cases of combined anterior-posterior PFV with minimal obstruction of the pupil may be observed. However, vitrectomy to sever 
Table 1 Persistent fetal vasculature classification

\begin{tabular}{|c|c|c|}
\hline & Mild & Severe \\
\hline Isolated anterior & $\begin{array}{l}\text { Retrolental plaque without extension onto ciliary } \\
\text { processes } \pm \text { cataract. No stalk or attachment to } \\
\text { posterior pole. } \\
\text { ( } 1 \text { eye }(2 \%) \text { of } 1 \text { patient) }\end{array}$ & $\begin{array}{l}\text { Retrolental plaque (often with vessels) with } \\
\text { extension onto ciliary processes } \pm \text { cataract. No } \\
\text { stalk or attachment to posterior pole. } \\
\text { ( } 3 \text { eyes }(7 \%) \text { of } 3 \text { patients) }\end{array}$ \\
\hline Isolated posterior & $\begin{array}{l}\text { Stalk or retinal fold with minimal to no optic nerve } \\
\text { or macular distortion. No attachment to lens or } \\
\text { ciliary processes. } \\
\text { ( } 1 \text { eye }(2 \%) \text { of } 1 \text { patient) }\end{array}$ & $\begin{array}{l}\text { Stalk or retinal fold with optic nerve or macular } \\
\text { distortion. No attachment to lens or ciliary } \\
\text { processes. } \\
\text { (0 eyes) }\end{array}$ \\
\hline $\begin{array}{l}\text { Combined } \\
\text { anterior-posterior }\end{array}$ & $\begin{array}{l}\text { Stalk (with minimal to no distortion of the optic } \\
\text { nerve or macula) connecting posterior pole to } \\
\text { retrolental plaque without extension onto ciliary } \\
\text { processes } \pm \text { cataract. } \\
\text { ( } 23 \text { eyes }(50 \%) \text { of } 23 \text { patients) }\end{array}$ & $\begin{array}{l}\text { Stalk (with moderate to severe distortion of the } \\
\text { optic nerve or macula) connecting posterior pole } \\
\text { to retrolental plaque with extension onto ciliary } \\
\text { processes } \pm \text { cataract. } \\
\text { (18 eyes }(39 \%) \text { of } 18 \text { patients) }\end{array}$ \\
\hline
\end{tabular}

the stalk connecting the posterior capsule and optic nerve can improve visual function by allowing for axial lengthening and alleviating posterior pole traction. ${ }^{18-20}$ Although there is limited data regarding a lens-sparing approach, maintaining phakic status in infants and young children is advantageous from an amblyopia standpoint. $^{2122}$ In cases in which the visual axis is blocked by cataract or retrolental membrane, the standard of care is lensectomy. ${ }^{23}$ Previous studies have shown that eyes with isolated anterior PFV have a better prognosis than eyes with posterior involvement due to the absence of macular and optic nerve pathology. ${ }^{20} 24-26$ Nevertheless, in anterior PFV that extends onto and beyond the ciliary processes, concurrent or subsequent core vitrectomy can decrease the risk of tractional retinal detachment, but may be limited by access to a multi-disciplinary surgical team. ${ }^{2728}$ Isolated posterior PFV often presents later, and surgical involvement may be dictated by retinal traction or detachment. Although eyes with severe PFV, especially those with retinal detachment, have poor visual prognosis, surgical intervention may help prevent phthisis and glaucoma. ${ }^{19}$ With the advent of modern surgical technology, PFV outcomes have improved overall, however, the rarity of the disease prevents large studies to fully assess outcomes. ${ }^{1923}$ 30-35 The purpose of this study is to add to the literature our 9-year predominantly surgical management of PFV and visual outcomes.

\section{METHODS}

A retrospective case series identified children younger than 18 years with PFV whose initial presentation to the Kellogg Eye Center at the University of Michigan was between January 2011 and January 2020.

Data collection included age, gender, ocular findings, type of PFV and visual acuity at presentation. Duration of follow-up and anatomic status and visual acuity at final visit were also included. Optotype visual acuity (Allen figures or Snellen) was attempted on cooperative patients typically 3 years of age or older. Optotype visual acuity was converted to LogMAR scale such that 20/200 and 20/20 were equivalent to 1 and 0.1 , respectively. Patients with visual acuity worse than $20 / 400$ were assessed by the ability to detect count fingers, hand motion or light and were not converted into LogMAR equivalents. Patients older than 3 months of age and/or uncooperative with optotype testing were assessed for ocular preference by induced tropia test with 10 base down prism. Individuals younger than 3 months of age were assessed for aversion to light as attentive fix and follow behaviour was not expected. At final follow-up, stable visual acuity was defined as within one line of initial optotype visual acuity or no change in ability to detect count fingers, hand motion or light. Improvement or decline in visual acuity was defined as two or more line change from initial optotype acuity or a change in ability to detect count fingers, hand motion or light.

Additionally, information regarding intraocular and strabismus surgeries, dates of surgeries, surgical procedure details and postoperative complications were collected. Exclusion criteria were surgical correction performed outside of our institution, age greater than 18 years at presentation, follow-up of less than 1 month, or isolated Mittendorf dot or Bergmeister papilla. PFV was classified clinically by location (anterior, posterior or combined anterior-posterior) and severity (mild or severe) (table 1). At the time of initial surgical intervention, all patients underwent examination under general anaesthesia.

Surgical procedure using the Constellation Vitreoretinal Surgical System (Alcon Laboratories, Fort Worth, Texas, USA) varied depending on ocular pathology and surgeon preference. Briefly for lensectomy, two 23-gauge limbal incisions were created for the vitrector hand piece and infusion port. The lens was removed with the vitrector. The posterior capsule followed by the anterior hyaloid were opened and a limited anterior vitrectomy was performed. For intraocular lens (IOL) placement, keratometry and axial length were obtained at the time of surgery and SRK-T lens equation was used to calculate the appropriate power. A foldable 3-piece (MA60AC, Alcon) or single-piece (SN60WF, Alcon) lens was chosen based on position within the sulcus or the capsule. The 
IOL was inserted through a superior scleral tunnel. For lens-sparing vitrectomy surgery, trocars were placed through the pars plana following the nomogram recommended by Lemley and Han. ${ }^{36}$ In aphakic eyes, trocars were placed just posterior to the limbus and surgery was performed transpupillary through the same trochar cannulae. In combined lensectomy-vitrectomy surgery, both procedures were performed through the same trocars/incisions. The posterior capsule and retrolental plaque were removed and in the process the stalk was severed. Endodiathermy was needed infrequently to cauterise bleeding hyaloidal vessels. A core vitrectomy was performed and posterior hyaloid membrane and cortical vitreous were dissected using aspiration and/or manual membrane peeling. In cases with severe anterior involvement, the 19-gauge or 23-gauge endoscope (Endo-Optiks, Little Silver, New Jersey, USA) was used to visualise the pars plicata, pars plana and ora serrata, identify posterior extension of the anterior plaque and apply photocoagulation to the peripheral retina as indicated.

Aphakic eyes were fit with a contact lens. The refractive target for contact lenses in patients under 2 years of age was -1.00 to -3.00 . After the age of 2 years, the contact lens refractive target was adjusted to plano and glasses with a +3.00 bifocal were dispensed. In patients unable to tolerate a contact lens, a secondary IOL, with a refractive target based on age, was placed if there was adequate capsular support. Patching of the preferred eye (amount per day dictated by age and visual acuity) was recommended for all amblyopic patients. Atropine penalisation of the preferred eye was used in some patients who did tolerate or were not compliant with patching.

GraphPad Prism 8 (GraphPad, La Jolla, California, USA) was used for statistical analyses using Wilcoxon and Student's t-tests. The reported $\mathrm{p}$ values were two-tailed. $P$ values of $<0.05$ were considered statistically significant.

\section{RESULTS}

Forty-five patients with PFV initially presented between January 2011 and January 2020. Median age at presentation was 2.8 months (mean $16.7 \pm 31.3$ months, range 0.7-138.0 months). Nineteen patients (42\%) were women and $26(58 \%)$ were men. Thirty-three patients $(72 \%)$ were Caucasian, seven (15\%) were African-American, four $(9 \%)$ were Asian and one (2\%) was Hispanic. Two patients had bilateral PFV, and both had confirmed genetic syndromes. Both eyes of one patient, who had mucopolysaccharidosis type VII (OMIM \#253220) were included. Only one eye of a patient with Microphthalmia, Syndrome 12 (OMIM \#180220) and Microcornea, Posterior megalolenticonus, Persistent fetal vasculature and Coloboma (MPPC) syndrome was included as the contralateral eye underwent initial surgery at an outside institution. Six patients with unilateral PFV had systemic congenital abnormalities (online supplemental table 1). Two patients had septo-optic dysplasia, both of whom had optic nerve hypoplasia in the contralateral eye. One patient with neurofibromatosis type 2 had retina/retinal pigment epithelium combined hamartomas in both eyes and an optic nerve glioma in the PFV eye. In three patients with systemic findings (Goldenhar syndrome, craniosynostosis and ventricular septal defect/dysmorphic features), the fellow eye was normal. One patient with no systemic abnormalities had MPCG syndrome in the PFV eye and showed optic nerve hypoplasia and chorioretinal coloboma in the contralateral eye. Another patient with unilateral PFV had a history of retinopathy of prematurity that required laser in both eyes.

Forty-six eyes of 45 patients were included in the analysis (online supplemental table 2) and there was a split between right and left eyes (23 eyes each). Mild combined anterior-posterior PFV was most common (23 eyes, $50 \%$ ), followed by severe combined anteriorposterior PFV (18 eyes, 39\%, table 1). Three eyes (7\%) had severe anterior and one eye $(2 \%)$ each had mild anterior or mild posterior PFV. At initial presentation, cataract (30 eyes, 65\%) and microphthalmia (16 eyes, $35 \%$ ) were most frequently associated with PFV (online supplemental table 3). Due to age and cooperation, only six patients (six eyes, 13\%) were cooperative for optotype visual acuity testing (LogMAR $0.3 \pm 0.2$, range $0.2-0.7$ ) at presentation (online supplemental table 2). Twenty-two eyes of 22 patients were aversive to light, all of whom were under 11 months of age including 16 who were under 3 months of age. Nine eyes of nine patients were not aversive to light while seven eyes of seven patients preferred the contralateral eye by induced tropia test. One eye each of the two patients with bilateral PFV was the preferred eye by induced tropia test. Patients who were able to cooperate for optotype testing were significantly older (79.9 \pm 30.8 months, range 57.1-138 months, $\mathrm{p}<0.0001$ ) than the 40 patients who could not complete optotype testing (7.2 \pm 17.4 months, range $0.7-105$ months).

Fourteen eyes of 13 patients did not undergo surgery (table 2). Nine eyes of eight patients had poor visual potential, seven of which were due to severe combined anterior-posterior $\mathrm{PFV}$ in combination with extreme microphthalmia and/or chronic retinal detachment. Two eyes had mild combined anterior-posterior PFV, but vision was limited either due to corneal opacification from mucopolysaccharidosis type VII or combined hamartoma of the retina/retinal pigment epithelium and optic nerve glioma due to neurofibromatosis type 2. Surgery was not required due to minimally visually significant PFV in four eyes of four patients with mild combined anterior-posterior PFV and one eye of one patient with mild posterior PFV.

Thirty-two eyes ( $70 \%$ of 46 eyes) of 32 patients underwent surgery for PFV at $10.1 \pm 20.9$ months (median 2.4 months, range 0.7-101 months) of age (table 2). Thirteen eyes ( $41 \%$ of 32 eyes) of 13 patients all with mild anterior-posterior combined PFV underwent lensectomy alone. Eleven eyes (34\% of 32 eyes) of 11 patients with either severe anterior PFV (three eyes) or severe combined anterior-posterior PFV (eight eyes) had combined lensectomy-vitrectomy. Three eyes $(9 \%$ of 32 
Table 2 Initial persistent fetal vasculature surgeries

\begin{tabular}{|c|c|c|c|c|c|c|}
\hline & $\begin{array}{l}\text { Mild } \\
\text { anterior } n=1 \\
(\% \text { of } n)\end{array}$ & $\begin{array}{l}\text { Mild posterior } n=1 \\
(\% \text { of } n)\end{array}$ & $\begin{array}{l}\text { Mild } \\
\text { combined } n=23 \\
(\% \text { of } n)\end{array}$ & $\begin{array}{l}\text { Severe } \\
\text { anterior } n=3 \\
(\% \text { of } n)\end{array}$ & $\begin{array}{l}\text { Severe } \\
\text { combined } n=18 \\
(\% \text { of } n)\end{array}$ & $\begin{array}{l}\text { Total } n=46 \\
(\% \text { of } n)\end{array}$ \\
\hline No surgery & & $\begin{array}{l}1 \text { eye } \\
(100 \%)\end{array}$ & $\begin{array}{l}6 \text { eyes } \\
(26 \%)\end{array}$ & & $\begin{array}{l}7 \text { eyes } \\
(39 \%)\end{array}$ & $\begin{array}{l}14 \text { eyes } \\
(30 \%)\end{array}$ \\
\hline Laser retinopexy & & & $\begin{array}{l}1 \text { eye } \\
(4 \%)\end{array}$ & & & $\begin{array}{l}1 \text { eye } \\
(2 \%)\end{array}$ \\
\hline Lensectomy & $\begin{array}{l}1 \text { eye } \\
(100 \%)\end{array}$ & & $\begin{array}{l}12 \text { eyes } \\
(52 \%)\end{array}$ & & & $\begin{array}{l}13 \text { eyes } \\
(28 \%)\end{array}$ \\
\hline Lensectomy-IOL & & & $\begin{array}{l}1 \text { eye } \\
(4 \%)\end{array}$ & & & $\begin{array}{l}1 \text { eye } \\
(2 \%)\end{array}$ \\
\hline Vitrectomy & & & $\begin{array}{l}3 \text { eyes } \\
(13 \%)\end{array}$ & & & $\begin{array}{l}3 \text { eyes } \\
(7 \%)\end{array}$ \\
\hline Lensectomy then vitrectomy* & & & & & $\begin{array}{l}3 \text { eyes } \\
(17 \%)\end{array}$ & $\begin{array}{l}3 \text { eyes } \\
(7 \%)\end{array}$ \\
\hline Lensectomy/vitrectomy† & & & & $\begin{array}{l}3 \text { eyes } \\
(100 \%)\end{array}$ & $\begin{array}{l}8 \text { eyes } \\
(44 \%)\end{array}$ & $\begin{array}{l}11 \text { eyes } \\
(24 \%)\end{array}$ \\
\hline
\end{tabular}

*Sequential lensectomy then vitrectomy.

†Combined lensectomy/vitrectomy surgery.

$\mathrm{IOL}$, intraocular lens.

eyes) of three patients with severe combined anteriorposterior PFV had sequential lensectomy then vitrectomy and three eyes (9\% of 32 eyes) of three patients with mild combined anterior-posterior PFV underwent vitrectomy alone. One eye ( $3 \%$ of 32 eyes) of one patient with mild combined anterior-posterior PFV each underwent lensectomy-IOL or laser retinopexy.

Twenty eyes of 20 patients, $63 \%$ of the surgical cohort (20/32 patients), required additional retinal surgery, glaucoma surgery, other anterior intraocular or strabismus surgery $(2.0 \pm 1.4$ surgeries/eye, range $1-6$, median 2) during follow-up (table 3). Five eyes, $16 \%$ of the surgical cohort (5/32 patients), all of which initially either underwent combined lensectomy-vitrectomy or sequential lensectomy then vitrectomy, required at least one additional vitrectomy surgery (online supplemental table $4,1.6 \pm 0.5$ vitrectomies/eye, range $1-2$, median 2 ) for retinal detachment (three eyes), retinal fold (one eye), cyclitic membrane (one eye) an average of $14.9 \pm 24.2$ months (range 1.2-58.1 months, median 5.4 months) after the initial PFV surgery. In our surgical cohort, 25\% (8/32 patients) were diagnosed with glaucoma (online supplemental table 5). In contrast, 7\% (1/14 patients) were diagnosed with glaucoma in the observation cohort.

\section{Table 3 Complications and additional surgeries}

\begin{tabular}{|c|c|c|c|c|}
\hline & $\begin{array}{l}\text { Additional } \\
\text { retinal } \\
\text { surgeries }\end{array}$ & $\begin{array}{l}\text { Glaucoma (\# } \\
\text { eyes requiring } \\
\text { glaucoma } \\
\text { surgery) }\end{array}$ & $\begin{array}{l}\text { Additional } \\
\text { anterior } \\
\text { intraocular } \\
\text { surgeries }\end{array}$ & $\begin{array}{l}\text { Strabismus } \\
\text { (\# patients } \\
\text { requiring } \\
\text { strabismus } \\
\text { surgery) }\end{array}$ \\
\hline \multicolumn{5}{|l|}{ No PFV surgery (14 eyes) } \\
\hline \multicolumn{5}{|l|}{ Mild posterior (1 eye) } \\
\hline Mild combined ( 6 eyes) & & & & 3 patients $(0)$ \\
\hline Severe combined (7 eyes) & & 1 eye $(0)$ & & 3 patients $(0)$ \\
\hline \multicolumn{5}{|l|}{ PFV surgery (32 eyes) } \\
\hline Mild anterior ( 1 eye) & & & & 1 patient (0) \\
\hline Mild combined (17 eyes) & & 3 eyes ( 1$)$ & 5 eyes & 15 patients (8) \\
\hline Severe anterior ( 3 eyes) & 1 eye & 1 eye (1) & 1 eye & 1 patient (0) \\
\hline Severe combined ( 11 eyes) & 4 eyes & 4 eyes $(4)$ & 2 eyes & 6 patients (1) \\
\hline Total & 5 eyes & 9 eyes $(6)$ & 8 eyes & 29 patients (9) \\
\hline No PFV surgery per cent (14 eyes) & 0 & 7 & 0 & 43 \\
\hline PFV surgery per cent (32 eyes) & 16 & 25 & 25 & 72 \\
\hline
\end{tabular}

PFV, persistent fetal vasculature. 
Six eyes, all of which underwent surgery for PFV $(75 \%$, $6 / 8$ patients), required glaucoma surgery to obtain intraocular pressure control (2.0 \pm 0.6 glaucoma surgeries/eye, range 1-3, median 2) an average of $33.4 \pm 39.1$ months (range 4.4-105.7 months, median 39.5 months) after the initial PFV surgery. Eight patients had additional anterior intraocular (non-glaucoma) surgeries $(1.2 \pm 0.5$ surgeries/eye, range 1-2, median 1) for secondary IOL placement (five eyes), pupilloplasty/synechiolysis (three eyes), repeat posterior capsulotomy (one eye) and attempted IOL placement (one eye) (online supplemental table 2). Three aphakic eyes required surgery for posterior capsular opacification, synechiae or membrane formation while one pseudophakic eye required a pupilloplasty. Twenty-nine of the patients had strabismus (19 esotropia, 10 exotropia), nine of which underwent eye muscle surgery $(1.2 \pm 0.4$ strabismus surgeries/patient, range $1-2$, median 1$)$.

At final follow-up (32.6 \pm 29.8 months, range 1.0-108.8 months, median 22.5 months), 42 eyes of 42 patients were amblyopic due to unilateral disease and had undergone part-time occlusion and/or atropine penalisation. One eye with mild posterior PFV had no amblyopia. In the patient with mucopolysaccharidosis type VII, although neither eye underwent surgery, the preferred eye had milder PFV compared with the non-preferred eye. In the patient with microphthalmia syndrome 12 and bilateral MPCC, only the preferred eye was included as the nonpreferred eye had undergo initial surgery at an outside institution. Twenty-two eyes of 22 patients were aphakic,
6 eyes of 6 patients had IOLs and 18 eyes of 17 patients were phakic. Of the 18 eyes that were phakic, 14 did not have surgery, 1 had laser retinopexy and 3 had vitrectomy alone.

Measurement of visual acuity was limited at presentation and final follow-up in many of the patients by age, cooperation and level of vision (online supplemental table 2). The majority of patients in the study, $91 \%$ (42/46 eyes), showed either improvement or stability of visual acuity at final follow-up (table 4 ). Within the PFV surgical cohort $66 \%$ (21/32 eyes) had improvement in visual acuity, $25 \%$ (8/32 eyes) showed stable visual acuity and $9 \%(3 / 32$ eyes) displayed worse visual acuity. The three eyes that had worse vision developed unrepairable retinal detachments and eventually became phthisical. Within the cohort that did not undergo surgical management for PFV, at final follow-up, 21\% (3/14 eyes) had improved visual acuity, $71 \%$ (10/14 eyes) showed no change in visual acuity and $7 \%$ (1/14 eyes) had worsened vision. At final follow-up, 12 eyes of 12 patients cooperated for optotype testing (online supplemental table 6, LogMAR $0.5 \pm 0.3$, range $0.1-1.1$, median 0.3 ). Eight of these 12 eyes were phakic (LogMAR $0.3 \pm 0.1$ ) and had significantly better vision $(\mathrm{p}=0.004)$ than the four eyes (LogMAR $0.8 \pm 0.4$ ) that were aphakic (two eyes) or pseudophakic (two eyes). Thirty-three patients (34 eyes) were unable to complete optotype testing. Six eyes were aversive to light and two eyes were able to count fingers at 4-8 inches. Eighteen eyes of 18 patients were able to fix and follow, with 16 of the patients showing a preference for

\begin{tabular}{|c|c|c|c|c|}
\hline & Improved vision & Stable vision & Worse vision & Total \\
\hline \multicolumn{5}{|l|}{ No surgery } \\
\hline Mild posterior & & 1 eye & & 1 eye \\
\hline Mild combined & 1 eye & 5 eyes & & 6 eyes \\
\hline Severe combined & 2 eyes & 4 eyes & 1 eye & 7 eyes \\
\hline \multicolumn{5}{|l|}{ Retinal laser } \\
\hline Mild combined & 1 eye & & & 1 eye \\
\hline \multicolumn{5}{|l|}{ Lensectomy or lensectomy-IOL } \\
\hline Mild anterior & 1 eye & & & 1 eye \\
\hline Mild combined & 9 eyes & 4 eyes & & 13 eyes \\
\hline \multicolumn{5}{|l|}{ Vitrectomy } \\
\hline Mild combined & 2 eyes & 1 eye & & 3 eyes \\
\hline \multicolumn{5}{|l|}{ Lensectomy then vitrectomy } \\
\hline Severe combined & 1 eye & & 2 eyes & 3 eyes \\
\hline \multicolumn{5}{|l|}{ Combined lensectomy/vitrectomy } \\
\hline Severe anterior & 3 eyes & & & 3 eyes \\
\hline Severe combined & 4 eyes & 3 eyes & 1 eye & 8 eyes \\
\hline Total & 24 eyes & 18 eyes & 4 eyes & 46 eyes \\
\hline No PFV surgery per cent (14 eyes) & 21 & 71 & 7 & \\
\hline PFV surgery per cent (32 eyes) & 66 & 25 & 9 & \\
\hline
\end{tabular}

IOP, intraocular lens; PFV, persistent fetal vasculature. 
the contralateral eye. Eight eyes were unable to detect light due to phthisis bulbi from chronic retinal detachment (seven eye) and optic nerve hypoplasia (one eye).

\section{DISCUSSION}

PFV is a significant cause of childhood blindness due to both the primary anatomic malformations and secondary complications such as retinal detachment, glaucoma and amblyopia. ${ }^{916}$ We describe our experience with PFV over a 9-year period assessing medical and surgical management and anatomic and functional outcomes in these complex eyes.

While over $90 \%$ of cases are sporadic and unilateral, there are rare cases of bilateral PFV which are typically associated with genetic syndromes. ${ }^{16}$ Of note, our study included two patients (4\%) with bilateral PFV. One patient had mucopolysaccharidosis type VII, an extremely rare form of mucopolysaccharidosis due to B-glucuronidase deficiency that often causes prenatal or perinatal death. ${ }^{37}$ Mucopolysaccharidosis type VII has not been previously correlated with PFV, thus it is unclear whether this ocular anomaly was coincidental or due to early fetal glycosaminoglycan deposition within the eye. The second patient had microphthalmia, syndrome 12, which is due to retinoic acid receptor beta mutations. ${ }^{38}$ Our patient also had a constellation of ocular findings known as MPPC, which is a very severe form of microphthalmia and PFV where the lens is posteriorly displaced and occupies the majority of the vitreous cavity. ${ }^{39}$ Another patient also had MPPC of one eye, while the contralateral eye showed optic nerve hypoplasia and peripheral chorioretinal coloboma. To date, this patient does not have systemic findings or a genetic diagnosis. Further, there are no confirmed genetic mutations associated with MPCC showing that additional studies are required on this severe eye abnormality. It is important to note that in addition to these three cases, five patients with unilateral PFV had systemic findings including neurofibromatosis type 2, septo-optic dysplasia, Goldenhar syndrome, craniosynostosis and ventricular septal defect. While many of these diseases have been previously associated with PFV, this serves as a reminder that even in unilateral cases, systemic diagnoses and contralateral eye findings should be investigated. ${ }^{10} 4041$

The decision for surgical management is based on patient age and visual prognosis as dictated by the type of PFV and associated macular and optic nerve abnormalities. Age at presentation has been shown to be a significant predictor of visual outcome, with previous reports demonstrating that early intervention leads to improved visual acuity. ${ }^{42}{ }^{43}$ While the average age of patients who underwent surgical management in our cohort was $10.1 \pm 20.9$ months, the median age was 2.4 months which is within the timeframe of critical visual development (6-10 weeks). Further, 23 of the 32 eyes undergoing surgery before 6 months of age, of which at final follow-up, 15 showed improved vision, 5 had stable vision and 3 had worse vision. Of the nine eyes who underwent surgery, there were two outliers who presented late ( 5 and 8 years of age) with mild amblyopia and subsequently underwent lens-sparing surgery for mild combined anterior-posterior PFV. Further, despite the higher mean age at surgery, our postoperative visual outcomes were comparable to a handful of studies in which at least 30 eyes with PFV underwent surgical intervention at mean ages between 2 and 3 months (table 5). ${ }^{19} 2030$

The type of PFV is a critical consideration in management. The majority of cases in many reports and in our series involve both the anterior and posterior fetal vasculatures. $^{19} 20233035$ Mild cases of combined PFV are characterised by a stalk with minimal optic nerve distortion that connects to the posterior capsule. In our study, the presence of a visually significant cataract or traction on the posterior pole dictated whether surgery was required. Based on this criteria, four eyes with mild combined anterior-posterior PFV did not require surgical management. An additional three eyes underwent lenssparing vitrectomy to relieve traction and one eye had laser retinopexy. Sparing of the lens in cases where there is not a visually significant cataract prevents aphakic/ pseudophakic anisometropia as well as amblyogenic loss of accommodation. ${ }^{21}{ }^{22}$ Certainly in our study, these three phakic patients had visual acuities of 20/40-20/60 at final follow-up. Other studies have also employed lenssparing vitrectomy, however, visual outcome data in these patients is limited as this is often a small subgroup of PFV (table 5). ${ }^{192030}$ Nevertheless, It is important to note that even with segmentation of the stalk, there may be astigmatic anisometropia from non-cataractous lens distortion that must be managed to treat amblyopia. Mild combined anterior-posterior PFV with a visually significant cataract is most commonly managed through lensectomy \pm IOL by an anterior segment surgeon or paediatric ophthalmologist. ${ }^{23} 243234$ In the majority of these cases, the visual potential is favourable. ${ }^{20} 2425$ However, unilateral aphakia and pseudophakia are highly amblyogenic, and so persistent and steadfast amblyopia management is required to attain $20 / 40$ or better visual acuity. ${ }^{22}{ }^{44}$ Similar to previous reports, in our study 3 of 14 eyes with mild combined anterior-posterior PFV which underwent lensectomy \pm IOL had visual acuity of $20 / 200$ or better and only one had visual acuity of $20 / 40 .^{23} 253235$

Severe PFV presents a more complicated problem due to inherent anterior and posterior abnormalities which predispose these eyes for retinal complications and glaucoma.In addition, involvement of the optic nerve and macula are associated with worse outcomes. ${ }^{19} 313345$ Due to these inherent congenital abnormalities, electrophysiology has been used to predict visual potential, and thus identify eyes in which surgery may not be beneficial. ${ }^{46}$ As a practice, we do not routinely conduct preoperative visual evoked potential testing, as there may be inaccuracies due to the age and inherent immaturity of the visual system in young infants. ${ }^{47}$ Instead we base the decision to perform surgery in these severe cases on the eye anatomy, initial 


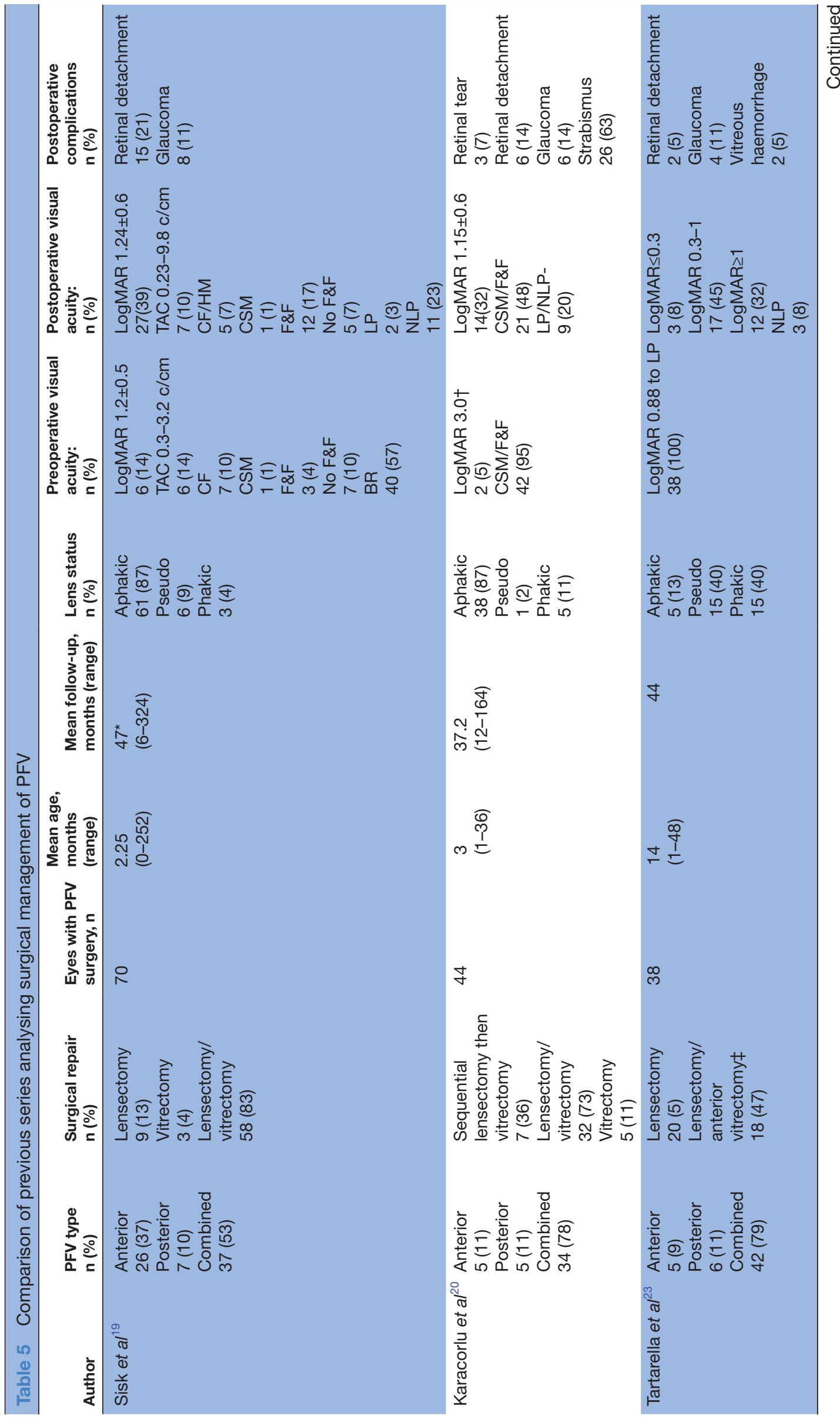




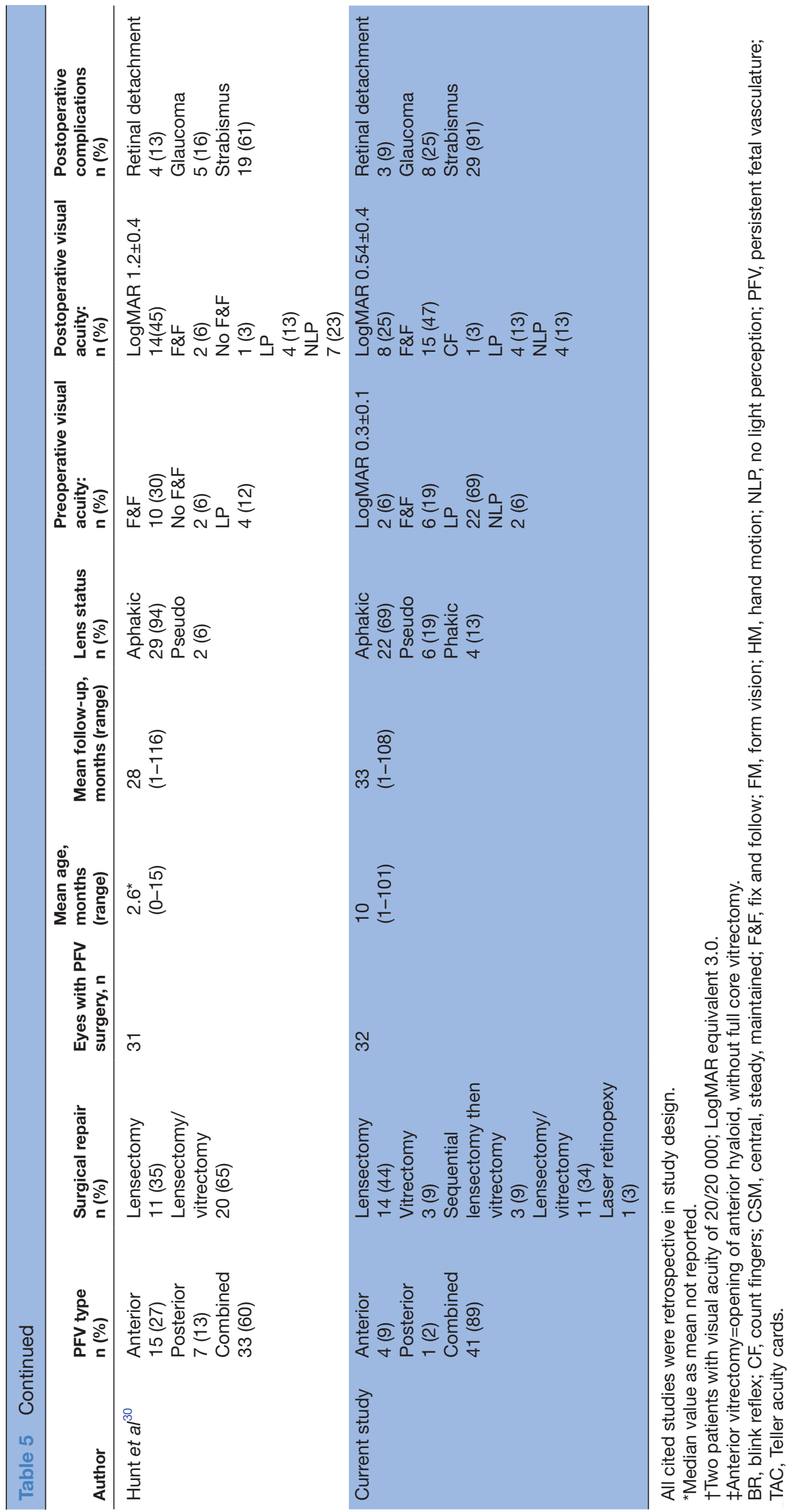


vision, status of the contralateral eye and parental desire. Observation is an option especially in cases where there is a closed funnel retinal detachment, severe optic hypoplasia and a normal contralateral eye. However, as the majority of these eyes, without intervention, eventually lose all vision from retinal detachment or glaucoma, we do tend to have a more aggressive approach. ${ }^{69} 31$ Of course this pro-surgical avenue requires in-depth discussion with the parents in order to manage expectations regarding visual outcomes and need for multiple surgeries. In our study, of the 18 eyes with severe combined PFV, surgery was not recommended for 7 eyes. In this observational cohort at final follow-up, $57 \%$ (4/7 eyes) were unable to detect light, of which three of these eyes $(43 \%)$ had phthisis from retinal detachment. In contrast, at final follow-up in the 11 severe combined PFV eyes that underwent surgical intervention, $27 \%$ (3/11 eyes) were unable to detect light due to phthisis bulbi. While surgical management of combined severe PFV poses challenges due to the risk of postoperative complications, similar to our results, previous studies have noted successful improvement in visual outcomes. ${ }^{278}$ Soheilian et al noted significant improvement in visual acuity in patients with combined PFV (OR 7.9, p value $=0.07$ ), possibly explained by anatomically successful retinal surgery, proper optical correction and amblyopia therapy. ${ }^{27}$ In addition, Mittra $e t$ al noted that $71 \%$ of patients presenting with combined PFV experienced improvement in final visual acuity of

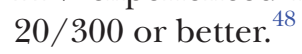

Previous studies have demonstrated modest results with lensectomy \pm vitrectomy, which may be performed from a pars plana or limbal approach. ${ }^{19} 203033$ Our management for severe anterior and severe combined anterior-posterior PFV was typically a combined lensectomy-vitrectomy surgery coordinated between paediatric anterior segment and retina specialists. The lens was first removed from an anterior approach, followed by a limbal vitrectomy which focused on careful inspection of the peripheral retina and segmentation of a stalk if present. This approach has also been successfully employed by other groups (table 5).$^{19}{ }^{20}{ }^{30}$ It is not uncommon for retrolental plaques to extend beyond the ora serrata causing traction and detachment of the peripheral retina. ${ }^{1749}$ Due to this we often employed the endoscope to visualise the pars plana and pars plicata to rule out posterior plaque extension and retinal traction. In some cases, retrolental plaque demonstrated focal to extensive posterior extension, leading to anterior retinal dragging and tenting of the retina over the pars plana and pars plicata. Endoscopic-guided vitrectomy in these cases reduces the rate of iatrogenic retinal breaks and intraoperative and postoperative retinal detachment. Endoscopy also allows the application of laser photocoagulation to the far periphery to surround focal retinal tractions and defects as needed..$^{50}$ Lack of adequate visualisation and treatment of the peripheral retina predisposes these eyes for retinal detachments complicated by retinal dialyses and proliferative vitreoretinopathy. The combined lensectomy-vitrectomy approach with anterior and posterior surgeons is advantageous over pars plana lensectomy and vitrectomy in that it often allowed for maintenance of capsular support for a future IOL. However, these eyes require close monitoring as there can be postoperative contracture of the remnant cyclitic/peripheral retinal membrane and capsule resulting in pupil constriction and in some cases tractional retinal detachment, iris bombe and glaucoma. ${ }^{173149}$ In our cohort, with this coordinated approach, 1 of the 11 eyes had worse vision due to an irreparable retinal detachment, while 10 of the eyes showed improved or stable vision at final follow-up. Like ours, other studies which used coordinated lensectomyvitrectomy surgery for PFV, also employed other surgical approaches (table 5). Nevertheless, there is a lack of visual and anatomic outcomes based on different surgical approaches in these prior reports. Thus, more studies focused on this coordinated approach are needed to verify that the effectiveness of establishing vision in these severely affected eyes that would otherwise likely be completely blind.

The advantage of the combined lensectomy-vitrectomy over sequential lensectomy then vitrectomy is less scarring by using the same incisions/ports and fewer exposures to general anaesthesia. In our series, the sequential surgeries in three eyes were not preoperatively planned, but due to the unanticipated finding that there was greater posterior segment involvement after lens removal. Similarly in Karacorlu et al, seven eyes first underwent lensectomy and then were referred to the retinal group for vitrectomy. ${ }^{20}$ In our cohort, this recategorised these three eyes from mild combined to severe combined PFV and necessitated subsequent vitrectomy which was performed within 2 weeks in two eyes. The third patient was lost to follow-up and vitrectomy was not completed until over a year later. Unfortunately, two of these eyes were phthisical at final follow-up. In Karacorlu et al, information regarding time between lensectomy and vitrectomy as well as visual outcomes in this subgroup are not reported. Thus, it is difficult to determine whether sequential surgeries, at least in our hands, had worse anatomic and visual outcomes compared with the combined lensectomy-vitrectomy.

Additional complications associated with PFV include retinal detachment and glaucoma. While mild anterior and mild combined PFV rarely have retinal complications, severe PFV are associated with vision compromising optic nerve and macular abnormalities as well as retinal detachments and folds. ${ }^{19433}$ In our cohort, $16 \%$ of eyes which underwent PFV surgery (5/32 eyes), all with severe $\mathrm{PFV}$, developed postoperative retinal detachments or tractional folds (following initial surgical intervention) that required additional vitrectomy. Three of these eyes had anatomic success and vision remained stable, while two became phthisical. Another eye developed an intraoperative irreparable retinal detachment at the time of initial vitrectomy and ultimately also developed phthisis. Our rate of postoperative retinal complications and 
phthisis is similar to other studies where these ranged from 5\%-21\% to $8 \%-23 \%$, respectively (table 5). ${ }^{19} 202330$ Thus, it is important to carefully monitor for postoperative retinal complications in eyes with PFV.

Glaucoma is a well-recognised complication of PFV and elevated intraocular pressure is often multi-factorial given early lens removal and additional congenital abnormalities. ${ }^{24} 49$ Glaucoma following cataract surgery (GFCS) is associated with early cataract removal, with the highest rates in eyes that have undergone surgery before 3 months of age ${ }^{52-54}$ However, previous studies have found no difference in the rate of glaucoma in aphakic eyes with or without $\mathrm{PFV}{ }^{34}$ Studies have demonstrated that unlike primary congenital glaucoma, medical therapy can be effective in over $50 \%$ eyes with GFCS. ${ }^{515}$ However, angle surgery has a lower success rate which is likely due to the different pathologies in eyes with congenital cataracts compared with primary congenital glaucoma. ${ }^{56}{ }^{57}$ In our cohort, 20\% (9/46) eyes were diagnosed with glaucoma, with the rate higher in the PFV surgery cohort $(25 \%$, $8 / 32$ eyes). This rate of glaucoma is higher than many of the previously published studies (table 5 ). This may be due to differences in the severity of PFV within the different reports, although these reports do not give specific details regarding which eyes developed elevated intraocular pressure. ${ }^{19202330}$ In our study, six of the nine eyes with glaucoma required surgery. Trabeculotomy was successful in one eye which had mild combined PFV. All eyes with severe forms of PFV and glaucoma also had microphthalmia, and required glaucoma drainage devices \pm cyclophotocoagulation to achieve Intraocular pressure (IOP) control. Few studies have specifically looked at the management of glaucoma in PFV, but rather categorise this with GCFS. A recent study showed that Ahmed glaucoma drainage devices were less successful and had a higher rate of complications in PFV compared with GCFS without PFV. ${ }^{58}$ In our study, Baerveldt glaucoma drainage devices were used in four eyes while an Ahmed was placed in one eye. Additional studies are required to better assess effective management of glaucoma in these severe PFV eyes.

The strengths of our study are the relatively high number of patients given the rarity of PFV. Limitations include the retrospective nature of the case series, variable disease severity at presentation, variable length of follow-up, and lack of control population. Further, although the study included 45 patients, 32 of whom underwent surgery for PFV, the total number of eyes in each surgical category is small. A prospective trial with greater volume of patients is difficult due to the rarity of PFV, although a multi-centre collaborative study would address this problem.

In conclusion, we reviewed our experience with PFV. While $70 \%$ of eyes underwent surgical correction for $\mathrm{PFV}$, it is important to note that some eyes do not require surgery either due to non-visually significant findings or poor visual potential. For eyes with visually significant findings, classification of PFV is critical for determining proper surgical management. While mild cases of PFV may be managed with lensectomy or vitrectomy alone, severe cases typically require both lensectomy and vitrectomy. In our hands, a combined lensectomy-vitrectomy surgical approach was most effective in establishing vision in these complex cases. Surgical management of $\mathrm{PFV}$, particularly in cases of significant posterior involvement, may have limited outcomes due to abnormal neuroretinal anatomy and postsurgical complications, including retinal detachment and glaucoma. In addition, the majority of these eyes also require appropriate treatments for amblyopia and strabismus to maximise visual potential. Our study provides additional information that paediatric ophthalmologists and retinal specialists can use during their consultation with the parents and guide the discussion of the meticulous management of PFV.

Contributors NK: data collection, manuscript preparation; CB: patient care, manuscript preparation; BLB: data collection, patient care, manuscript preparation.

Funding The authors have not declared a specific grant for this research from any funding agency in the public, commercial or not-for-profit sectors.

Competing interests None declared.

Patient consent for publication Not required.

Ethics approval This study was approved by the Institutional Review Board at the University of Michigan (exemption) in adherence to the tenants of the Declaration of Helsinki. As a retrospective study, it was not appropriate or possible to involve patients or the public in the design, or conduct, or reporting, or dissemination plans of our research.

Provenance and peer review Not commissioned; externally peer reviewed.

Supplemental material This content has been supplied by the author(s). It has not been vetted by BMJ Publishing Group Limited (BMJ) and may not have been peer-reviewed. Any opinions or recommendations discussed are solely those of the author(s) and are not endorsed by BMJ. BMJ disclaims all liability and responsibility arising from any reliance placed on the content. Where the content includes any translated material, BMJ does not warrant the accuracy and reliability of the translations (including but not limited to local regulations, clinical guidelines, terminology, drug names and drug dosages), and is not responsible for any error and/or omissions arising from translation and adaptation or otherwise.

Open access This is an open access article distributed in accordance with the Creative Commons Attribution Non Commercial (CC BY-NC 4.0) license, which permits others to distribute, remix, adapt, build upon this work non-commercially, and license their derivative works on different terms, provided the original work is properly cited, appropriate credit is given, any changes made indicated, and the use is non-commercial. See: http://creativecommons.org/licenses/by-nc/4.0/.

ORCID iD

Brenda L Bohnsack http://orcid.org/0000-0001-8961-6343

\section{REFERENCES}

1 Mets MB. Childhood blindness and visual loss: an assessment at two institutions including a "new" cause. Trans Am Ophthalmol Soc 1999;97:653-96.

2 Chen C, Xiao H, Ding X. Persistent fetal vasculature. Asia Pac J Ophthalmol 2019;8:86-95.

3 Khaliq S, Hameed A, Ismail M, et al. Locus for autosomal recessive nonsyndromic persistent hyperplastic primary vitreous. Invest Ophthalmol Vis Sci 2001;42:2225-8.

4 Prasov L, Masud T, Khaliq S, et al. Atoh7 mutations cause autosomal recessive persistent hyperplasia of the primary vitreous. Hum Mol Genet 2012;21:3681-94.

5 Weissgold DJ, Maguire AM, Kalin NS, et al. Persistent hyperplastic primary vitreous in association with Aicardi syndrome. J Pediatr Ophthalmol Strabismus 1995;32:52-4.

6 Goldberg MF. Persistent fetal vasculature (PFV): an integrated interpretation of signs and symptoms associated with persistent 
hyperplastic primary vitreous (PHPV). LIV Edward Jackson memorial lecture. Am J Ophthalmol 1997;124:587-626.

7 Steichen-Gersdorf E, Gassner I, Unsinn K, et al. Persistent hyperplastic primary vitreous in a family with osteoporosispseudoglioma syndrome. Clin Dysmorphol 1997;6:171-6.

8 Pendergast SD, Trese MT, Liu X, et al. Study of the Norrie disease gene in 2 patients with bilateral persistent hyperplastic primary vitreous. Arch Ophthalmol 1998;116:381-23.

9 Shastry BS. Persistent hyperplastic primary vitreous: congenital malformation of the eye. Clin Experiment Ophthalmol 2009;37:884-90.

10 Nguyen DQ, Chatterjee S, Bates R. Persistent hyperplastic primary vitreous in association with neurofibromatosis 2 . J Pediatr Ophthalmol Strabismus 2005;42:247-9.

11 Dhingra S, Shears DJ, Blake V, et al. Advanced bilateral persistent fetal vasculature associated with a novel mutation in the Norrie gene. Br J Ophthalmol 2006;90:1324-5.

12 Teske MP, Trese MT. Retinopathy of prematurity-like fundus and persistent hyperplastic primary vitreous associated with maternal cocaine use. Am J Ophthalmol 1987;103:719-20.

13 Suzuki K, Nakamura M, Amano E, et al. Case of chromosome 6p25 terminal deletion associated with Axenfeld-Rieger syndrome and persistent hyperplastic primary vitreous. Am J Med Genet $A$ 2006;140A:503-8

14 Muslubas IS, Hocaoglu M, Arf S, et al. A case of morning glory syndrome associated with persistent hyperplastic primary vitreous and Peters' anomaly. GMS Ophthalmol Cases 2017;7:Doc02.

15 Pollard ZF. Results of treatment of persistent hyperplastic primary vitreous. Ophthalmic Surg 1991;22:48-52.

16 Cerón O, Lou PL, Kroll AJ, et al. The vitreo-retinal manifestations of persistent Hyperplasic primary vitreous (PHPV) and their management. Int Ophthalmol Clin 2008;48:53-62.

17 Zahavi A, Weinberger D, Snir M, et al. Management of severe persistent fetal vasculature: case series and review of the literature. Int Ophthalmol 2019;39:579-87.

18 Shaikh S, Trese MT. Lens-Sparing vitrectomy in predominantly posterior persistent fetal vasculature syndrome in eyes with nonaxial lens opacification. Retina 2003;23:330-4.

19 Sisk RA, Berrocal AM, Feuer WJ, et al. Visual and anatomic outcomes with or without surgery in persistent fetal vasculature. Ophthalmology 2010;117:2178-83.

20 Karacorlu M, Hocaoglu M, Sayman Muslubas I, et al. Functional and anatomical outcomes following surgical management of persistent fetal vasculature: a single-center experience of 44 cases. Graefes Arch Clin Exp Ophthalmol 2018;256:495-501.

21 Repka MX. Visual rehabilitation in pediatric aphakia. Dev Ophthalmol 2016;57:49-68.

22 Bothun ED, Wilson ME, Traboulsi El, et al. Outcomes of unilateral cataracts in infants and toddlers 7 to 24 months of age. Ophthalmology 2019;126:1189-95.

23 Tartarella MB, Takahagi RU, Braga AP, et al. Persistent fetal vasculature: ocular features, management of cataract and outcomes. Arq Bras Oftalmol 2013;76:185-8.

24 Jinagal J, Gupta PC, Ram J, et al. Outcomes of cataract surgery in children with persistent hyperplastic primary vitreous. Eur J Ophthalmol 2018;28:193-7.

25 Yeh C-T, Chen K-J, Liu L, et al. Visual and anatomical outcomes with vitrectomy in posterior or combined persistent fetal vasculature in an Asian population. Ophthalmic Surg Lasers Imaging Retina 2019;50:377-84.

26 Promelle V, Bryselbout S, Milazzo S. Visual prognosis of posterior and combined persistent fetal vasculature. Eur J Ophthalmol 2020;30:284-8.

27 Soheilian M, Vistamehr S, Rahmani B, et al. Outcomes of surgical (pars plicata and limbal lensectomy, vitrectomy) and non-surgical management of persistent fetal vasculature (PFV): an analysis of 54 eyes. Eur J Ophthalmol 2002;12:523-33.

28 Ozdek S, Ozdemir Zeydanli E, Atalay HT, et al. Anterior elongation of the retina in persistent fetal vasculature: emphasis on retinal complications. Eye 2019;33:938-47.

29 Gulati N, Eagle RC, Tasman W. Unoperated eyes with persistent fetal vasculature. Trans Am Ophthalmol Soc 2003;101:59-65.

30 Hunt A, Rowe N, Lam A, et al. Outcomes in persistent hyperplastic primary vitreous. Br J Ophthalmol 2005;89:859-63.

31 Walsh MK, Drenser KA, Capone A, et al. Early vitrectomy effective for bilateral combined anterior and posterior persistent fetal vasculature syndrome. Retina 2010;30:S2-8.

32 Vasavada AR, Vasavada SA, Bobrova N, et al. Outcomes of pediatric cataract surgery in anterior persistent fetal vasculature. J Cataract Refract Surg 2012;38:849-57.
33 Bosjolie A, Ferrone P. Visual outcome in early vitrectomy for posterior persistent fetal vasculature associated with traction retinal detachment. Retina 2015;35:570-6.

34 Kuhli-Hattenbach C, Hofmann C, Wenner Y, et al. Congenital cataract surgery without intraocular lens implantation in persistent fetal vasculature syndrome: long-term clinical and functional results. $J$ Cataract Refract Surg 2016:42:759-67.

35 Li L, Fan D-B, Zhao Y-T, et al. Surgical treatment and visual outcomes of cataract with persistent hyperplastic primary vitreous. Int J Ophthalmol 2017;10:391-9.

36 Lemley CA, Han DP. An age-based method for planning sclerotomy placement during pediatric vitrectomy: a 12-year experience. Retina 2007;27:974-7.

37 Sands MS. Mucopolysaccharidosis type VII: a powerful experimental system and therapeutic challenge. Pediatr Endocrinol Rev 2014;12 Suppl 1:159-65.

38 Slavotinek A. Genetics of anophthalmia and microphthalmia. Part 2: Syndromes associated with anophthalmia-microphthalmia. Hum Genet 2019;138:831-46.

39 Ranchod TM, Quiram PA, Hathaway N, et al. Microcornea, posterior Megalolenticonus, persistent fetal vasculature, and coloboma. Ophthalmology 2010;117:1843-7.

40 Dattani MT, Martinez-Barbera JP, Thomas PQ, et al. Hesx1: a novel gene implicated in a familial form of septo-optic dysplasia. Acta Paediatr 1999;88:49-54.

41 Rooijers W, Caron CJJM, Loudon SE, et al. Ocular and adnexal anomalies in craniofacial microsomia: a systematic review. Int J Oral Maxillofac Surg 2020;49:1107-14.

42 Karr DJ, Scott WE. Visual acuity results following treatment of persistent hyperplastic primary vitreous. Arch Ophthal 1986;104:662-7.

43 Pollard ZF. Persistent hyperplastic primary vitreous: diagnosis, treatment and results. Trans Am Ophthalmol Soc 1997;95:487-549.

44 Yusuf IH, Patel CK, Salmon JF. Unilateral persistent hyperplastic primary vitreous: intensive management approach with excellent outcome beyond visual maturation. BMJ Case Rep 2015;2015:bcr2014206525.

45 Schulz E, Griffiths B. Long-Term visual function and relative amblyopia in posterior persistent hyperplastic primary vitreous (PHPV). Strabismus 2006;14:121-5.

46 Dass AB, Trese MT. Surgical results of persistent hyperplastic primary vitreous. Ophthalmology 1999;106:280-4.

47 Russell Harter M, Deaton FK, Vernon Odom J. Maturation of evoked potentials and visual preference in 6-45-day-old infants: effects of check size, visual acuity, and refractive error. Electroencephalogr Clin Neurophysiol 1977;42:595-607.

48 Mittra RA, Huynh LT, M.s R. Visual outcomes following lensectomy and vitrectomy for combined anterior and posterior persistent hyperplastic primary vitreous. Arch Ophthal 1998;116:1190-4.

49 Warren N, Trivedi RH, Wilson ME. Persistent fetal vasculature with elongated ciliary processes in children. Am J Ophthalmo 2019;198:25-9.

50 Bowe T, Rahmani S, Yonekawa Y. Endoscopic vitrectomy for microcornea, posterior megalolenticonus, persistent fetal vasculature, coloboma syndrome. Ophthalmology 2017;124:1742.

$51 \mathrm{Kim} \mathrm{J-A,} \mathrm{Lee} \mathrm{S-Y,} \mathrm{Park} \mathrm{KH,} \mathrm{et} \mathrm{al.} \mathrm{Incidence} \mathrm{and} \mathrm{risk} \mathrm{factors} \mathrm{for}$ glaucoma development after bilateral congenital cataract surgery in microphthalmic eyes. Am J Ophthalmol 2019;208:265-72.

52 Chen TC, Walton DS, Bhatia LS. Aphakic glaucoma after congenital cataract surgery. Arch Ophthal 2004;122:1819-25.

53 Chen TC, Bhatia LS, Halpern EF, et al. Risk factors for the development of aphakic glaucoma after congenital cataract surgery. Trans Am Ophthalmol Soc 2006;104:241-51.

54 Freedman SF, Lynn MJ, Beck AD, et al. Glaucoma-related adverse events in the first 5 years after unilateral cataract removal in the infant aphakia treatment study. JAMA Ophthalmol 2015;133:907-14.

55 Freedman SF, Kraker RT, Repka MX, et al. Incidence and management of glaucoma or glaucoma suspect in the first year after pediatric lensectomy. JAMA Ophthalmol 2020;138:71-5.

56 Lim ME, Dao JB, Freedman SF. 360-degree trabeculotomy for medically refractory glaucoma following cataract surgery and juvenile open-angle glaucoma. Am J Ophthalmol 2017;175:1-7.

57 Rojas C, Bohnsack BL. Rate of Complete Catheterization of Schlemm's Canal and Trabeculotomy Success in Primary and Secondary Childhood Glaucomas. Am J Ophthalmol 2020;212:69-78.

58 Spiess K, Peralta Calvo J. Outcomes of Ahmed glaucoma valve in paediatric glaucoma following congenital cataract surgery in persistent foetal vasculature. Eur J Ophthalmol 2020:1120672120919066. 